\title{
Pharmacological models of amnesia: A reexamination of the effects of cholinergic muscarinic antagonist scopolamine and NMDA-receptor antagonist MK-801 on delayed nonmatching-to-position in rats
}

\author{
JOHN K. ROBINSON \\ State University of New York, Stony Brook, New York
}

\begin{abstract}
Cholinergic muscarinic receptor antagonist scopolamine and glutamatergic NMDA receptor antagonist MK-801 have been used as pharmacological agents to assess the contributions of their respective neurotransmitter systems to memory processing, but they produce sedative and motor disruption that may mask effects on memory measures. To explore the influence of these nonspecific effects on delayed nonmatching-to-position (DNMTP), the effects of scopolamine were compared with those of MK801 on a DNMTP paradigm modified to simultaneously assess discrimination and working memory. Both scopolamine and MK-801 produced significant reductions in rate at which trials were completed, largely accounted for in the case of scopolamine by a failure in responding to the sample stimulus. Scopolamine also produced an increase in position bias and increased responding on a random-ratio schedule during the retention interval. MK-801 produced no effects on these measures. Neither drug produced significant effects on DNMTP choice accuracy, the measure of working memory. These results suggest that effects on nonmnemonic behavioral parameters may have contributed to previously reported working memory disruptions.
\end{abstract}

It has been known for almost two decades that Alzheimer's disease $(A D)$ is marked by reduction in the levels of several neurotransmitters. Acetylcholine is one of those neurotransmitters whose markers are consistently reduced across studies and most reliably correlated with cognitive impairments (Coyle, Price, \& DeLong, 1982; Davies \& Maloney, 1976; Reisine, Yamamura, Bird, Spokes, \& Enna, 1978). Therefore, cholinergic system enhancers, such as physostigmine and tacrine, have been studied as possible drug therapies for Alzheimer's disease (Boller \& Forrette, 1989).

Scopolamine, a cholinergic muscarinic receptor antagonist, has been shown in humans to produce cognitive and memory disruption analogous to dementia (Molchan et al., 1992). Numerous animal studies have examined the effects of cholinergic antagonists, such as atropine and scopolamine, on learning and memory (Hagan \& Morris, 1988; Olton \& Wenk, 1987). Most show disruption of performance of learning and memory tasks. However, the effects of higher doses of scopolamine also produce motor

The author would like to thank Matthew Kunchandy, Christine Patten, Tinamarie Pollizoto, Toni Graceffo, and Nicholas Renzi for assistance in conducting these experiments, and Jian-Bin Mao, Howard Eichenbaum, David Emmerich, Marci Lobel, and Alex Stevens for helpful suggestions. This work was supported by Grant 1 RO3 MH 552 90-01 from NIMH. Correspondence should be addressed to J. K. Robinson, Department of Psychology, SUNY, Stony Brook, NY 11794 2500 (e-mail: jrobinson@ccmail.sunysb.edu). effects such as hyperactivity and stereotypy (See Hagan \& Morris, 1988, for a review).

A model of synaptic plasticity that could underlie memory formation has developed in parallel, but independently of, the cholinergic model of Alzheimer's dementia. It emerged from the initial observation that the postsynaptic response of dentate gyrus neurons was enhanced following the delivery of a high-frequency train of stimulation delivered through the perforant path, termed long-term potentiation (LTP; Bliss \& Lomo, 1973). Studies have suggested that an important form of this LTP is critically dependent on glutamatergic $N$-methy-D-aspartate (NMDA) receptors (Baudry \& Lynch, 1988; Cotman, Monaghan, \& Ganong, 1988). As would be predicted, NMDA receptor antagonists block LTP in anesthesized animals (Abraham \& Mason, 1988). Behavioral studies have supported this observation. Morris, Anderson, Lynch, and Baudry (1986) showed that doses of NMDA receptor antagonist AP5 that blocked LTP also impaired the learning of the water maze task. Other studies have since demonstrated disruption of learning and memory tasks (e.g., Butelman, 1990; Jones, Bauerle, \& DeNoble, 1990; Shapiro \& Caramanos, 1990; Staubli, Thibault, DiLorenzo, \& Lynch, 1989). However, it is possible that motor disruption or sedative effects of MK- 801 could account for some of the memory deficits in these motorically demanding maze tasks (Whishaw \& Auer, 1989; Willets, Balster, \& Leander, 1990; Wozniak, Olney, Kettinger, Price, \& Miller, 1990). 
One alternative to the maze memory paradigms for rodents has been the delayed nonmatching-to-position (DNMTP) paradigm. This task is conceptually similar to the delayed matching-to-sample (DNMTS) task used extensively in primates (see Mishkin, 1982; Squire, 1992, for reviews). Lesions to hippocampal, basal forebrain, thalamic, and cortical regions have generally produced memory effects in rodent matching- or nonmatching-to-position comparable to those produced by lesions to these structures in primates (see Cohen \& Eichenbaum, 1994, for a review). However, both scopolamine and MK-801 have been shown to disrupt DNMTP choice accuracy in a manner independent of delay interval, a pattern interpreted to indicate a disruption of capabilities extending beyond a simple impairment of working memory (Bushnell, 1990; Dunnett, 1985; Robinson \& Crawley, 1993b; Sakurai \& Wenk, 1990; Tan, Kirk, Abraham, \& McNaughton, 1989). In either case, the rat's ability to attend to the complex task procedures could have been compromised as a result of motor alterations or sedational effects of the drugs. An additional consideration comes from several recent studies that have suggested a role for basal forebrain cholinergic systems in mediating attention (Muir, Dunnett, Robbins, \& Everitt, 1992; Pang, Williams, Egeth, \& Olton, 1993; Voytko et al., 1994). So, in either case, it is possible that previous disruptions of DNMTP performance are partly or largely attributable to nonmnemonic disruption.

The present study represents an attempt to remove the influence of discrimination disruption and other nonspecific effects from DNMTP memory measurement. The DNMTP procedure was aitered to measure ongoing discrimination during performance of the task, and to distinguish it from memory. In the present study, the effects of systemically administered muscarinic receptor antagonist scopolamine were compared with those of NMDA receptor antagonist MK-801 on this modified DNMTP paradigm.

\section{METHOD}

\begin{abstract}
Subjects
The subjects were 26 male, Sprague-Dawley rats, 120 days old at the beginning of the experiment. They were housed individually in plastic tub cages in a humidity- and temperature-controlled vivarium and were maintained on a 12:12-h light:dark cycle (lights on at 7:00 a.m.). All procedures were performed in accordance with the NIH Guide for the Care and Use of Laboratory Animals (U.S. DHHS, 1985 ) and with the approval of the SUNY Stony Brook IACUC.
\end{abstract}

\footnotetext{
Apparatus

The subjects were tested in computer-controlled operant test chambers, equipped with one rear-mounted and two front-mounted response levers. A cue lamp was in place over each, and water reinforcers were delivered into a front water aperture. This apparatus has been described in detail previously (Robinson \& Crawley, 1993b).

\section{Behavioral Testing}

A DNMTP trial consisted of three phases:

Sample phase. A 3-sec tone was followed by a brief $(500-\mathrm{msec})$ illumination of one of the front cue lamps. A press on that lever within $3 \mathrm{sec}$ of the offset of the sample cue was followed by illumination of the rear cue lamp.
}

Retention phase. A retention interval consisting of equal numbers of 0.1-, 2-, 4-, 8-, or 16-sec delays, intermixed throughout the session.

Choice phase. The first press on the rear cue following within $3 \mathrm{sec}$ the completion of the retention interval illuminated both front cue lamps. Because of this requirement and the uncertainty of the duration of the retention interval, the rats typically pressed the rear lever steadily $(>0.5$ presses $/ \mathrm{sec}$ ) throughout the entire duration of the retention interval.

A press on the lever not pressed (a "nonmatch-to-position") during the sample phase produced a $0.1-\mathrm{ml}$ water reward followed by a 10-sec intertrial interval (ITI). A press on the same lever pressed during the sample phase produced only the ITI. Choice phase accuracy as a function of retention interval was the primary measure of working memory. The primary measures of discrimination were as follows:

Sample-phase discrimination errors. Presses on the lever not cued during the 3 -sec sample response period. This bias free measure was calculated by the method of Frey and Colliver (1973), modified for a two-choice signal detection used here, where $C=$ correct responses on either lever, and $I=$ incorrect responses on either lever. The formula is:

$$
\text { Sensitivity Index }=(C-I) /\left[2(C+I)-(C+I)^{2}\right] .
$$

Sample-phase response omissions. A failure to press on either front lever during the 3-sec sample response period. This measure assesses the general response tendency of the rat and presumably can be influenced by any behavior that diverts the subject's sensory apparatus away from the cue lamps or reduces motivation to respond.

Anticipatory responses. Responses occurring during the auditory warning stimulus.

Additionally, position bias, a measure of response preference for one of the two levers, was calculated for sample responses. This response bias measure (absolute deviation from chance) was calculated by subtracting the proportion of responses to the left lever from the expected value (.5), then converting that number to a positive number to equilibrate individual left- and right-lever biases. It is important to note that choice errors, response omissions, and anticipatory responses are followed by a return to the ITI, rather than the initiation of the retention phase.

Subjects were extensively pretrained to greater than $90 \%$ choice accuracy at the 0.1-sec delay, as described previously (Robinson \& Crawley, 1993a, 1993b, 1994; Robinson, Wenk, Wiley, Lappi, \& Crawley, 1996). The subjects then received training on DNMTP with the variable delays $(0.1-16 \mathrm{sec})$ until performance at the $0.1-\mathrm{sec}$ delay stabilized at $>90 \%$, prior to and again after surgery before injections were performed.

\section{Drugs}

Injections were given on Tuesdays and Thursdays, with intervening Monday, Wednesday, and Friday baseline days. A subject who had performed less than $90 \%$ correct on the $0.1-, 2-$, and 4-sec retention intervals on the prior baseline day was not administered a drug injection on the next test day. Following retraining, saline or scopolamine $(0.12,0.25$, or $0.5 \mathrm{mg} / \mathrm{kg}$, dissolved in saline) or MK$80 \mathrm{l}(0.06,0.12$, or $0.25 \mathrm{mg} / \mathrm{kg}$, dissolved in saline) was administered $10 \mathrm{~min}$ prior to the start of the test session. The subjects received no more than one injection of each dose of drug, though some animals received less than four injections of each. The scopolamine drug series was administered over several weeks first and then followed by the MK-801 series.

\section{RESULTS}

Figure 1 shows the number of trials completed per session and sample-phase response omissions, both as a function of dose of either scopolamine or MK-801. For 
scopolamine, a significant decrease in trials completed per 40-min session $[F(3,42)=10.2, p<.0001]$ and a significant increase in errors of omission $[F(3,42)=7.4$, $p<.0004]$ are shown. A similar, though not as pronounced, decrease in trials completed $[F(3,55)=3.5, p<.02]$ and a nonsignificant trend to an increase in errors of omission $[F(3,55)=1.8, p<.15]$ were observed for MK-801.

Figure 2 shows an analysis of the sample response discrimination accuracy, expressed as a sensitivity index, on the left $y$-axis, and a measure of response bias, absolute deviation from chance, on the right $y$-axis. For scopolamine, no decrease in sample-phase discrimination accuracy $[F(3,30)=1.4]$ was detected. In contrast, an increased response bias $[F(3,41)=4.5, p<.008$; the 0.5 dose was significantly different from saline by Dunnett's test, $p<.05]$ was detected. No change in sample-phase discrimination accuracy $[F(3,50)=1.5]$ or increased re- sponse bias $[F(3,53)=1.4]$ was detected for MK-801. No significant effect on anticipatory responses was detected for either scopolamine $[F(3,42)=1.7]$ or $\mathrm{MK}-801$ $[F(3,55)=.84]$.

Forgetting functions were calculated for subjects at each dose who completed more than 20 trials per session; these are shown in Figure 3. Although a trend toward a delay-dependent reduction of the frequency of correct responses was produced by scopolamine, no significant effect was detected [main effect, $F(3,24)=1.0, p<.38$; delay $\times$ dose interaction, $F(3,12)=1.5, p<.14$ ]. MK801 also produced some disruption of choice accuracy that approached significance [main effect, $F(3,40)=2.7$, $p<.06$; delay $\times$ dose interaction, $F(3,12)=1.6, p<.09$ ]. If no criterion for trial completion was applied, delaydependent reduction of the frequency of correct responses was produced by scopolamine [main effect, $F(3,29)=$
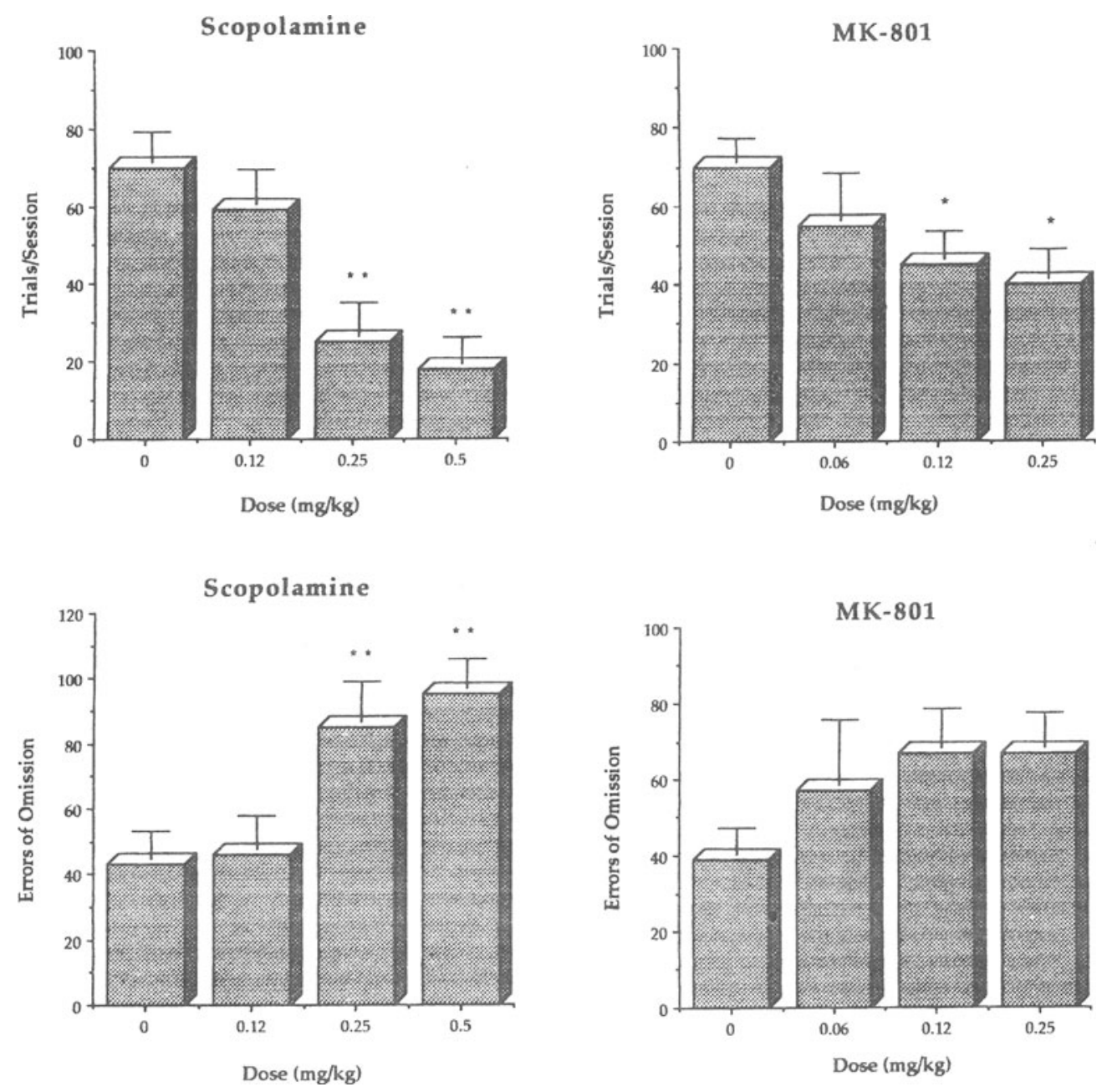

Figure 1. Number of trials completed per session and sample-phase response omissions as a function of dose of either scopolamine or MK-801: For scopolamine and MK-801, there is a significant decrease in trials completed per 40-min session, and for scopolamine only, a significant increase in errors of omission. The numbers of subjects in each group was as follows: Scopolamine-saline $=12, .12 \mathrm{mg} / \mathrm{kg}=9, .25 \mathrm{mg} / \mathrm{kg}=12$, $.50 \mathrm{mg} / \mathrm{kg}=13 ; \mathrm{MK-801}-$ saline $=16, .06 \mathrm{mg} / \mathrm{kg}=8, .12 \mathrm{mg} / \mathrm{kg}=15, .25 \mathrm{mg} / \mathrm{kg}=20$. For Figures $1-4$, the means $( \pm S E M)$ are shown. ${ }^{*} p<.05$ by Dunnett's test. ${ }^{* *} p<.01$ by Dunnett's test. 

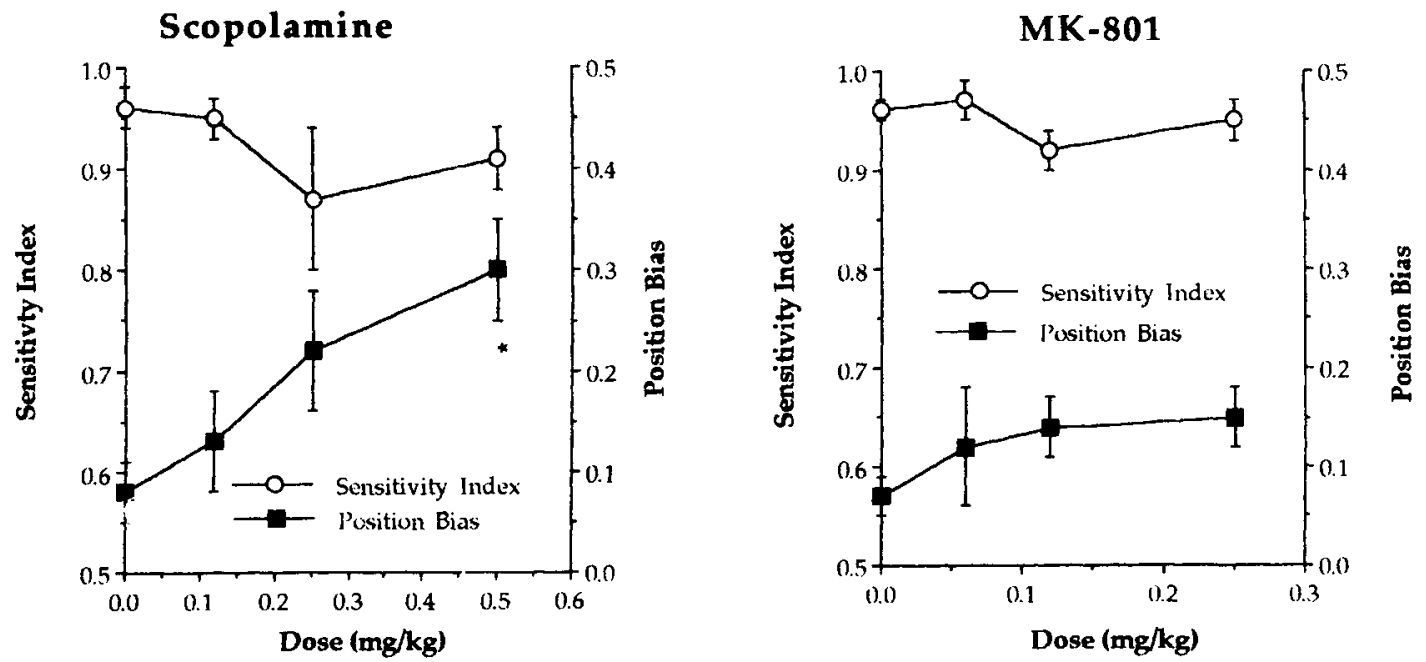

Figure 2. Sensitivity index for sample responses is shown on the left $y$-axis, and a measure of sample-phase position bias is shown on the right $y$-axis. An increase in position bias was detected for scopolamine, but not for MK-801. No significant change in the sensitivity index was detected for scopolamine or for MK-801. The numbers of subjects in each group were as follows: scopolamine- saline $=12, .12 \mathrm{mg} / \mathrm{kg}=9, .25 \mathrm{mg} / \mathrm{kg}=11, .50 \mathrm{mg} / \mathrm{kg}=13 ; \mathrm{MK}-801-$ saline $=16, .06 \mathrm{mg} / \mathrm{kg}=8, .12 \mathrm{mg} / \mathrm{kg}=14, .25 \mathrm{mg} / \mathrm{kg}=19$.

$1.1, p<.38 ;$ delay $\times$ dose interaction, $F(3,12)=2.1, p<$ $.02]$. Because of the significant interaction, one-way analyses of variance were performed for each delay. These one-way analyses revealed significant effects only at the $0.1-\sec [F(3,32)=2.9, p<.04]$ and $8.0-\sec [F(3,30=$ $2.8, p<.05]$ retention intervals. Dunnett's test $(p<.05)$ showed that only the $0.5-\mathrm{mg} / \mathrm{kg}$ dose group was significantly different from the saline group at the $0.1-\mathrm{sec}$ retention interval, and that only the $0.25-\mathrm{mg} / \mathrm{kg}$ dose group was significantly different from the saline group at the 8.0 -sec retention interval. The trends for MK- 801 remained nonsignificant when no trial completion criterion was applied to the data set [main effect, $F(3,47)=2.5$, $p<.07$; delay $\times$ dose interaction, $F(3,12)=1.4, p<.16$ ]

Figure 4 shows the retention-interval rear-lever responses per trial, as a function of dose of either scopolamine or MK-801. Because the retention interval is selected randomly from the five possible values, it is unpredictable to the subject. Therefore, this response requirement is formally a random-ratio schedule of reinforcement and provides an index of operant response rate. For scopolamine, a significant increase in response rate is shown $[F(3,32)=3.1, p<.04]$. Dunnett's test $(p<.05)$ showed that only the $0.5-\mathrm{mg} / \mathrm{kg}$ dose group was significantly different from the saline group. In contrast, no change in response rate is shown for MK- 801 $[F(3,54)=1.8]$.

\section{DISCUSSION}

In the present study, the effects of scopolamine were compared with those of MK-801 on a DNMTP paradigm modified to simultaneously assess task discrimination and working memory. Both scopolamine and MK-801 at larger doses reduced the rate at which trials were com- pleted. Sample-phase errors of omission were also shown to increase for scopolamine, and this increase accounted for the reduction in trial completion rate. Scopolamine produced a linear increase in position bias, some impairment of accuracy of responding to the sample stimulus, and an increase in operant rear-lever response rate. MK801 produced no effects on these measures.

Both drugs produced some alteration of DNMTP choice accuracy, though not reliably in either case. This decrease in effects on the accuracy of choice represents a considerable attenuation of the degree of disruption reported in previous studies (Bushnell, 1990; Dunnett, 1985; Robinson \& Crawley, 1993b; Tan et al., 1989). For example, Robinson \& Crawley (1993b) reported that delay-independent disruptions of choice accuracy produced by a $0.5-\mathrm{mg} / \mathrm{kg}$ dose of scopolamine approached chance responding at all retention intervals, with numbers of subjects per group comparable to those in the present study.

This attenuation of impairment of choice responding may be accounted for by the procedural difference between the present, modified DNMTP and versions used in previous studies. The cancellation of trials on which the subject responded prior to the presentation, responded slowly or inaccurately to the sample, or failed to promptly make choice responses following completion of the retention interval could be conceived of as eliminating trials on which encoding might have been superficial because of poor attention to the sample stimulus. To state this in another way: they remembered better because they attended better on the trials that they had to remember. The second possible explanation stems from the requirement that for forgetting functions to be calculated reliably, a minimum number of completed trials was requiredspecifically, one at each of the five retention intervals. However, a minimum number of 20 was established as 

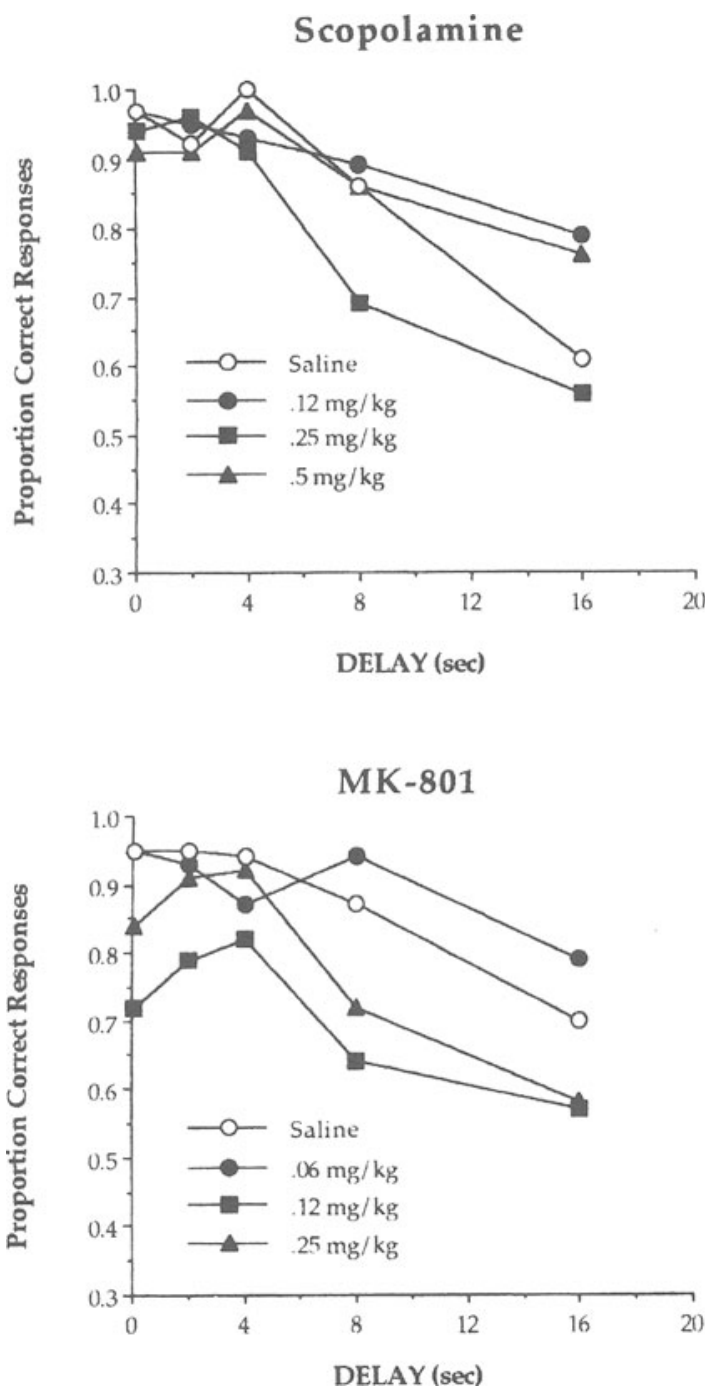

Figure 3. Means of the proportion correct choice responses as a function of retention interval (delay). Differences for both drugs were determined to be nonsignificant by analyses of variance. The numbers of subjects in each group were as follows: scopolaminesaline $=12, .12 \mathrm{mg} / \mathrm{kg}=8, .25 \mathrm{mg} / \mathrm{kg}=7, .50 \mathrm{mg} / \mathrm{kg}=6$; MK801 -saline $=15, .06 \mathrm{mg} / \mathrm{kg}=6, .12 \mathrm{mg} / \mathrm{kg}=12, .25 \mathrm{mg} / \mathrm{kg}=11$.

the quota for inclusion, in an attempt to ensure that the measure was reasonably reliable. This restriction eliminated the performances of some subjects from the calculation of forgetting functions as the number of trials completed diminished. This occurred especially at the highest doses of each drug. Therefore, the forgetting functions were calculated only from animals that were less affected on the discrimination parameters by the drugs, and that were perhaps less affected by the drugs generally.

The reduction of trial completion rate was shown to be almost entirely accounted for by an increase in sampleresponse omissions. The requirement that the animals respond to the sample within a brief 3 -sec period produces a fair number of response omissions even in control conditions. This value for the hold period was chosen in order to minimize confounding of the measure with memory demand. It is clear that both drugs produced substantial increases in this measure, but for what reason? It is possible that two different effects of the drugs could account for these increases. As shown in Figure 4, retention-interval random-ratio response rate was significantly increased by scopolamine, but not by MK-801. This raises the possibility that scopolamine produced hyperactivity at the $0.25-\mathrm{mg} / \mathrm{kg}$ and $0.5-\mathrm{mg} / \mathrm{kg}$ doses, perhaps diminishing attending to the sample stimulus. What might explain the increase in sample response omissions for MK-801 is not clear. What can be said is that the lack of change in rearlever response rate would suggest that hyperactivity or motor disturbance cannot explain the increase.

What do these data say about the attempt to assess in rats the involvement of the cholinergic and glutamatergic neurotransmitter systems in memory processes? In the case of both drugs, it appears that as the secondary effects of the drugs are accounted for, disruption of working memory also can be seen to have diminished. This implies that neither are involved in mediating working memory processes. However, it is possible that these non-
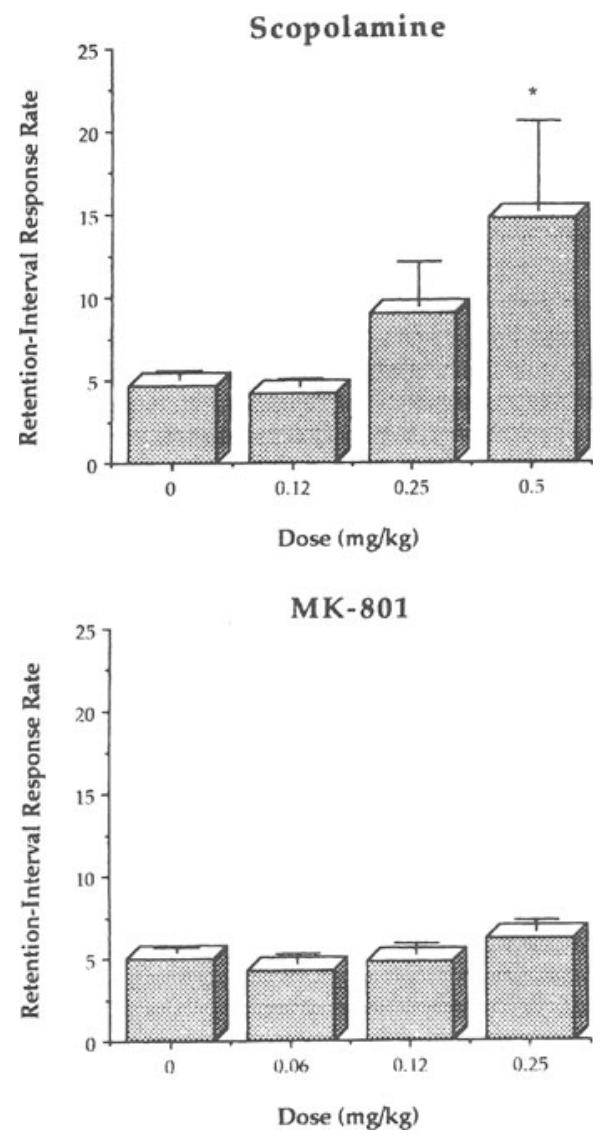

Figure 4. Number of responses per trial occurring on the rear lever during the retention interval. Scopolamine, but not MK801 , produced a significant increase in response rate. The numbers of subjects in each group were as follows: scopolamine-saline = $12, .12 \mathrm{mg} / \mathrm{kg}=8, .25 \mathrm{mg} / \mathrm{kg}=8, .50 \mathrm{mg} / \mathrm{kg}=8 ; \mathrm{MK}-801-$ saline $=16, .06 \mathrm{mg} / \mathrm{kg}=8, .12 \mathrm{mg} / \mathrm{kg}=15, .25 \mathrm{mg} / \mathrm{kg}=19$. 
mnemonic effects that cause increases in response omissions simply mask effects upon working memory. One limitation of the present study is that the systemic route of administration produces what is probably a summation of effects at different brain sites. One way to circumvent this problem is to administer the drugs to specific brain regions by microinjection. Dunnett, Wareham, and Torres (1991) showed that scopolamine microinjected into the prefrontal cortex and hippocampus produced delaydependent disruption of DNMTP, but that scopolamine microinjected into the caudate produced delay-independent disruption. Robinson and Crawley (1993a) microinjected scopolamine into the medial septum and also reported delay-independent disruption of DNMTP. Recently, Robinson and Mao (in press) have shown differential disruption of DNMTP by scopolamine and MK-801 in the dorsal but not the ventral hippocampus, confirming and extending Dunnett et al.'s (1991) finding. Together, these studies showing differential effects of scopolamine at brain sites suggest that in future studies the effects of muscarinic and NMDA receptor antagonism should be systematically compared in cortex, septum, and hippocampal sites so that we may better understand the roles and possible interactions of cholinergic and glutamatergic systems in distinct brain regions.

In conclusion, we should consider the degree to which both scopolamine and MK-801 may continue to be useful as pharmacological models of amnesia. First, it is interesting that the pattern of effects produced by scopolamine was distinct from that produced by MK -801 . Although both drugs produced some reduction of trial completion rate, scopolamine produced more consistent disruption of the measures of position bias and response tendency. Second, neither produced significant delayed choice accuracy deficits. If these observations are evaluated together, it seems safe to conclude that both drugs, when given systemically, are poor choices for pharmacological modeling of amnesia. However, both drugs may still be useful as models of other kinds of impairments. The pattern of impairments produced by scopolamine in the present study, as well as in other behavioral paradigms (Hagan \& Morris, 1988), still may have reasonable face validity for modeling the profound composite deficits in Alzheimer's disease that we might describe as "confusion." Likewise, MK-801, because of its disruptive effects on LTP, may still be a good model of learning deficits, defined explicitly as the acquisition of longlasting discriminated responses or stimulus associations, phenomena deliberately not investigated presently.

\section{REFERENCES}

Abraham, W. C., \& Mason, S. E. (1988). Effects of the NMDA receptor/channel antagonists CPP and MK-801 on hippocampal field potentials and long-term potentiation in anesthesized rats. Brain Research, 462, 40-46.

BaUdry, M., \& LynCH, G. (1988). Properties and substrates of mammalian memory systems. In H. Y. Meltzer (Ed.), Psychopharmacology: The third generation of progress (pp. 449-462). New York: Raven.

BLISS, T. V. P., \& LoMO, T. (1973). Long-lasting potentiation of synap- tic transmission in the dentate area of the anesthesized rabbit following stimulation of the perforant path. Journal of Physiology, 232, 331-356.

Boller, F., \& Forrette, F. (1989). Alzheimer's disease and THA: A review of the cholinergic theory and of preliminary results. Biomedicine \& Pharmacotherapy, 43, 487-491.

BUSHNELL, P. J. (1990). Modeling working and reference memory in rats: Effects of scopolamine on delayed matching-to-position. $\mathrm{Be}$ havioral Pharmacology, 1, 419-427.

ButelmaN, E. R. (1990). The effect of NMDA antagonists in the radial arm maze task with an interposed delay. Pharmacology, Biochemistry \& Behavior, 35, 533-536.

Cohen, N. J., \& Eichenbaum, H. (1994). Memory, amnesia, and the hippocampal system. Cambridge, MA: MIT Press.

Cotman, C. W., Monaghan, D. T., \& Ganong, A. H. (1988). Excitatory amino acid neurotransmission: NMDA receptors and Hebb-type synaptic plasticity. Annual Review of Neuroscience, 11, 61-80.

Coyle, J. T., Price, D. L. \& DeLong, M. R. (1982). Alzheimer's disease: A disorder of cortical cholinergic innervation. Science, 219 , 1184-1190.

Davies, P., \& Maloney, A. J. F. (1976). Selective loss of central cholinergic neurons in Alzheimer's disease. Lancet, 2, 1403.

DunNeTt, S. B. (1985). Comparative effects of cholinergic drugs and lesions of the fimbria-fornix on delayed matching in rats. Psychopharmacology, 87, 357-363.

Dunnett, S. B., Wareham, A. T., \& Torres, E. M. (1991). Cholinergic blockade in prefrontal cortex and hippocampus disrupts shortterm memory in rats. Neuroreport, 1, 61-64.

Frey, P. W., \& Colliver, J. A. (1973). Sensitivity and responsivity measures for discrimination learning. Learning \& Motivation, 4, 327-342.

HaGan, J. J., \& MoRris, R. G. M. (1988). The cholinergic hypothesis of memory: A review of animal experiments. In L. L. Iversen, S. D. Iversen, \& S. H. Snyder (Eds.), Handbook of psychopharmacology: Psychopharmacology of the aging nervous system (Vol. 20, pp. $217-$ 323). New York: Plenum.

Jones, K. W., Bauerle, L. M., \& DeNoble, V. J. (1990). Differential effects of $\sigma$ and phencyclidine receptor ligands on learning. European Journal of Pharmacology, 179, 97-102.

Mishrin, M. (1982). A memory system in the monkey. Philosophical Transactions of the Royal Society of London: Series B, 209, 85-95.

Molchan, S. E., Martinez, R. A., Hill, J. A., Weingartner, H. J., Thompson, K., Vitiello, B., \& SUnderland, T. (1992). Increased cognitive sensitivity to scopolamine with age and a perspective on the scopolamine model. Brain Research Reviews, 17, 215-226.

Morris, R. G. M., ANDERSON, E., LyNCH, G. S., \& BAUdRY, M. (1986). Selective impairment of learning and blockade of long-term potentiation by an $N$-methyl-D-aspartate receptor antagonist, AP5. Nature, 319, 774-776.

Muir, J. L., Dunnett, S. B., Robbins, T. W., \& Everitt, B. J. (1992). Attentional functions of the forebrain cholinergic systems: Effects of intraventricular hemicholinium, physostigmine, basal forebrain lesions and intracortical graphs on a multiple-choice serial reaction time task. Experimental Brain Research, 89, 611-622.

Olton, D. S., \& WENK, G. L. (1987). Dementia: Animal models of the cognitive impairments produced by degeneration of the basal forebrain cholinergic system. In H. Y. Meltzer (Ed.), Psychopharmacology: The third generation of progress (pp. 941-953.). New York: Raven.

PanG, K., Williams, M. J., Egeth, H., \& Olton, D. S. (1993). Nucleus basalis magnocellularis (NBM) and attention: Effects of muscimol injections. Behavioral Neuroscience, 107, 1031-1038.

Reisine, T. D., Yamamura, H. I., Bird, E. D., Spokes, E., \& EnNa, S. J. (1978). Pre- and post-synaptic neurochemical alterations in Alzheimer's disease. Brain Research, 159, 477-482.

Robinson, J. K., \& Crawley, J. N. (1993a). Intraseptal galanin potentiates scopolamine impairment of delayed nonmatching to sample. Journal of Neuroscience, 13, 5119-5125.

Robinson, J. K., \& CRAWLEY, J. N. (1993b). Intraventricular galanin impairs delayed nonmatching-to-sample performance in the rat. $B e$ havioral Neuroscience, 107, 458-467.

Robinson, J. K., \& CRAWLEY, J. N. (1994). Analysis of anatomical sites at which galanin impairs delayed nonmatching to sample in rats. Behavioral Neuroscience, 108, 941-950. 
RoBINSON, J. K., \& MAO, J.-B. (in press). Differential effects on delayed nonmatching-to-position in rats of microinjections of muscarinic receptor antagonist scopolamine and NMDA receptor antagonist MK801 into dorsal or ventral extents of the hippocampus. Brain Research.

Robinson, J. K., WENK, G. L., WILEY, R. G., LAPPI, D. A., \& CRAWLey, J. N. (1996). ${ }^{192} \mathrm{IgG}$-Saporin immunotoxin and ibotenic acid lesions of the nucleus basalis and medial septum produce comparable deficits on delayed nonmatching to position in rats. Psychobiology, 24, 179-186.

SaKURAI, Y., \& WENK, G. (1990). The interaction of acetylcholinergic and serotonergic neural systems on performance in the continuous nonmatching to sample task. Brain Research, 519, 118-121.

Shapiro, M. L., \& Caramanos, Z. (1990). NMDA antagonist MK-801 impairs acquisition but not performance of spatial working and reference memory. Psychobiology, 18, 231-243.

SQuiRE, L. R. (1992). Memory and the hippocampus: A synthesis of findings from rats, monkeys, and humans. Psychological Review, 99 , 195-231

Staubli, U., Thibault, O., Dilorenzo, M., \& Lynch, G. (1989). Antagonism of NMDA receptors impairs acquisition but not retention of olfactory memory. Behavioral Neuroscience, 103, 54-60.
TAN, S., Kirk, R. C., Abraham, W. C., \& MCNaughton, N. (1989). Effects of the NMDA antagonists CPP and MK-801 on delayed conditional discrimination. Psychopharmacology, 98, 556-560.

U.S. Department of Health and Human Services (1985). NIH guide for the care and use of laboratory animals (Publication No. NIH 85-23. Washington, DC: U.S. Government Printing Office.

Voytko, M. L., Olton, D. S., Richardson, R. T., Gorman, L. K., TOBIN, J. R., \& PRICE, D. R. (1994). Basal forebrain lesions in monkeys disrupt attention but not learning and memory. Journal of Neuroscience, 14, 167-186.

Whishaw, I. Q., \& AUER, R. N. (1989). Immediate and long-lasting effects of MK-801 on motor activity, spatial navigation in the swimming pool and EEG in the rat. Psychopharmacology, 98, 500-507.

WILLETS, J., BALSTER, R. L., \& LEANDER, J. D. (1990). The behavioral pharmacology of NMDA receptor antagonists. Trends in Pharmacological Sciences, 11, 423-428.

Wozniak, D. F., Olney, J. W., Kettinger, L., III, Price, M., \& MiLLER, J. P. (1990). Behavioral effects of MK-801 in the rat. Psychopharmacology, 101, 47-56.

(Manuscript received December 3, 1996; revision accepted for publication April 29, 1997.) 